EDITORIAL

Rev Obstet Ginecol Venez. 2021; 81 (3): 195-199.

https://doi.org/10.51288/00810303

\title{
Inmunidad colectiva contra la COVID-19
}

\author{
Dra. Mireya González Blanco
}

Directora/Editora

El término inmunidad colectiva, también llamada inmunidad de grupo o inmunidad de rebaño, se refiere a la protección indirecta contra una enfermedad infecciosa que se consigue cuando un grupo poblacional se vuelve inmune, ya sea como resultado de la vacunación o de haber presentado la infección con anterioridad. La Organización Mundial de la Salud(OMS) apoya la postura de lograr la inmunidad colectiva mediante la vacunación, no permitiendo que una enfermedad se propague en un grupo demográfico, ya que ello daría como resultado que se presentaran casos y defunciones innecesarios. El porcentaje de personas que deben ser inmunes para conseguir la inmunidad colectiva varía en cada caso. Se desconoce la proporción de personas a la que se le debe aplicar la vacuna contra la COVID-19 para comenzar a observar inmunidad colectiva. Determinar esa proporción es un tema de investigación fundamental, pero se sabe que para lograrla de una manera segura, una proporción considerable tendría que vacunarse, lo que reduciría la cantidad total de virus que podría propagarse entre toda la población (1).

En todo el mundo, los datos sobre seroprevalencia sugieren que menos del $10 \%$ de los casos estudiados han sido infectados, lo que significa que una inmensa mayoría, a nivel mundial, sigue siendo vulnerable a este virus (1).

Forma de citar este artículo: González Blanco M. Inmunidad colectiva contra la COVID-19. Rev Obstet Ginecol Venez. 2021; 81(3):195-199. https://doi.org/10.51288/00810303
Recientemente, se publicó una nota en Nature, que describe las razones por las que la inmunidad de rebaño podría no alcanzarse (2). La nota fue traducida al español y adaptada por NavarroAlonso (3), quien es miembro del Comité Editorial de la Asociación Española de Vacunología. A continuación, se revisan algunos puntos que destacan en ese texto, acompañados de comentarios que podrían ser de ayuda para superar esas razones.

Hasta hace poco se creía que cuando haya mucha gente vacunada se bloqueará la transmisión y se alcanzará el umbral de la inmunidad de rebaño, pero esto, comienza a parecer poco probable. La mayoría de los expertos hablaba de llegar a un $60 \%-70 \%$ de población inmune, bien por padecimiento o por vacunación, pero a medida que avanza la pandemia, este concepto parece cambiar. Da más la impresión de que la COVID-19 llegará a ser una enfermedad endémica $(2,3)$.

La clave de la inmunidad de rebaño reside en que si una persona se infecta, a su alrededor habrá muy pocos susceptibles que puedan mantener y formar parte de la cadena de transmisión. Las vacunas disponibles, unas más, otras menos, son extremadamente efectivas en evitar la enfermedad sintomática pero se sabe, que no protegen contra la adquisición del virus. La inmunidad de rebaño solo es relevante si la vacuna bloquea la transmisión. Si no es así, la única manera de obtenerla es vacunando al $100 \%$ de las personas. Sin embargo, no hace falta que bloquee por completo la transmisión, con un $70 \%$ ya se observarían resultados sorprendentes, 
pero todavía habría mucha cantidad de virus circulante en la comunidad $(2,3)$.

Importa mucho la velocidad y la distribución de la vacuna. Teóricamente, una campaña mundial perfectamente coordinada podría eliminar la pandemia, pero a la vista de la situación es altamente improbable que se consiga. Hay una tremenda disparidad en la distribución de vacunas (2). La OMS, además de agilizar la búsqueda y el desarrollo de vacunas seguras y eficaces contra la COVID-19, ayuda a aumentar la capacidad de producción y colabora con los gobiernos y los fabricantes para garantizar la asignación justa y equitativa de vacunas a todos los países, a través del Mecanismo COVAX, que es la única iniciativa mundial que persigue esta meta. La OMS dirigió la elaboración de un marco para la asignación equitativa, destinado a asegurar que las vacunas y los tratamientos eficaces contra la COVID-19 se distribuyan de forma equitativa entre todos los países. Todos los países deberían recibir un número de dosis proporcional al número de sus habitantes, a fin de inmunizar a los grupos de máxima prioridad $\mathrm{y}$, posteriormente, se seguirían distribuyendo las vacunas a todos los países para que estos puedan vacunar a otros grupos en función de las prioridades nacionales. El objetivo de COVAX es proporcionar al menos 2000 millones de dosis de vacunas para finales de 2021 y 1800 millones de dosis a 92 economías de ingresos bajos para principios de 2022 (4). Lamentablemente, a la fecha, por distintas razones, Venezuela no ha podido acceder al mecanismo COVAX, aunque la Organización Panamericana de la Salud (OPS) indicó que Venezuela recibirá las vacunas correspondientes al mecanismo COVAX en dos rondas aunque aún no se tiene fecha exacta para su llegada: en una primera ronda de distribución, la nación sudamericana recibirá unas 2,6 millones de vacunas de Sinopharm y unas 600000 de Sinovac y posteriormente, Venezuela recibiría vacunas adicionales de Sinopharn para completar hasta 5 millones de esta vacuna (5).
Según Our World in Data (6), un proyecto del Global Change Data Lab, una organización sin ánimo de lucro, $33 \%$ de la población mundial ha recibido, por lo menos, una dosis de la vacuna contra la COVID-19; más de cinco billones de dosis han sido administradas globalmente y 36,21 millones de dosis son administradas diariamente; sin embargo, solo $1,6 \%$ de la gente de países de bajos recursos ha recibido aunque sea una dosis. Estos datos hacen más que evidente esa disparidad. En Venezuela, según la misma fuente (6), para el 12 de julio de este año, solo 3,8 \% de los habitantes del país (1,1 millones de personas) había recibido dos dosis y $6,3 \%$ adicional (1,8 millones) había recibido una dosis. Datos actualizados al 17 de agosto, señalan que se habían aplicado 16,3 dosis de vacuna por cada 100 personas. Con estos datos, el país ocupa el tercer lugar más bajo, solo por encima de Haití $(0,24 \%)$ y Nicaragua $(9,14 \%)$.

Es una paradoja que en algunos países se disponga de la vacuna y miles de personas se niegan a ser vacunados, mientras que en otros, las personas buscan afanosamente la posibilidad de ser vacunados. Los organismos internacionales y las instancias nacionales deben redoblar esfuerzos para reducir las diferencias, en el entendido claro y definitivo de que la pandemia solo se controlará efectivamente si la inmunidad es uniforme, global. Individualmente, hay que educar, insistir, promover la vacunación, aclarar dudas, contribuir con asesoría a nivel de la familia, la comunidad y, sobre todo, entre las pacientes, muchas de ellas gestantes, quienes expresan temores infundados.

Por otro lado, las nuevas variantes cambiarán la ecuación de la inmunidad de rebaño. Se puede observar un resurgimiento de los casos, a pesar de un alto nivel de inmunidad, cuando aparecen nuevas variantes del virus que no se ven neutralizadas por las vacunas. Para evitarlo sería muy importante vacunar rápida y simultáneamente en todo el planeta $(2,3)$. Mientras que la investigación sugiere que las vacunas contra la COVID-19 son 
levemente menos efectivas contra las variantes, vacunarse todavía parece proporcionar protección contra una COVID-19 de gravedad. Investigaciones tempranas del Reino Unido sugieren que, después de completarse la vacunación, la vacuna de PfizerBioNTech contra la COVID-19 tiene una efectividad del $88 \%$ en la prevención del virus sintomático de la COVID-19 causado por la variante delta. La vacuna demostró tener una efectividad del $96 \%$ en la prevención de una enfermedad grave y del $93 \%$ en la prevención del virus sintomático de la COVID-19 causado por la variante alfa. Así mismo, investigaciones tempranas en Canadá sugieren que, después de una dosis, la vacuna de Moderna contra la COVID-19 tiene una efectividad del $72 \%$ en la prevención del virus sintomático causado por la variante delta. Una dosis de la vacuna también tiene una efectividad del $96 \%$ en la prevención de una enfermedad grave causado por la misma variante. La vacuna de Janssen de Johnson \& Johnson contra la COVID-19 demostró tener una efectividad del $85 \%$ en la prevención de una enfermedad grave por la variante delta (7).

Es posible que la respuesta ante las variantes sea levemente menor que ante el virus original, sin embargo, también es cierto que mientras más se tarde en obtener la cobertura vacunal de la mayor parte de la población, más riesgo hay de que se produzcan nuevas mutaciones del virus y, con ellas, surjan nuevas variantes, lo que definitivamente retardaría el control de la fase aguda de la pandemia.

Otro aspecto importante es que se desconoce cuál será la duración de la inmunidad, tanto natural como inducida por la vacunación. Es decir, no se sabe la duración de la protección posvacunal y si serán necesarios refuerzos vacunales periódicos $(2,3)$. Con relación a este punto, continúan las investigaciones. Es importante saber cuánto durará la inmunidad para saber si es necesario aplicar un refuerzo o varios refuerzos en forma periódica, pero lo que sí sabemos, y aunque parezca una perogrullada, hay que decirlo, es que si las personas no están vacunadas, el proceso de desarrollo de la inmunidad no se inicia a menos, claro está, que se desarrolle inmunidad natural al adquirir la enfermedad que, justamente, se trata de prevenir. Una vez más, mientras la comunidad de investigadores obtiene la respuesta, el trabajo está ahí, en estimular a las personas para que se vacunen.

Un punto muy importante, en el que se puede trabajar directamente, para evitarlo, es en el cambio de conducta de los vacunados. Poco a poco, comienza a aumentar la interrelación social, condición que puede modificar la ecuación de la inmunidad de rebaño, ya que esta descansa, en parte, en cuántas personas se exponen al virus. Se debe continuar con las medidas no farmacológicas de contención $(2,3)$.

E1 Centro de Control de Enfermedades (CDC) recomienda, a las personas completamente vacunadas, esto es, dos semanas después de la segunda dosis, cuando se usan esquemas de vacunación de dos dosis, como es el caso de Venezuela, que pueden reanudar las actividades que hacían antes de la pandemia; usar una mascarilla en público en espacios cerrados para reducir el riesgo de infección por la variante delta y evitar contagiar a los demás; usar mascarilla en otras situaciones si es una persona de alto riesgo por edad, condición inmunológica o morbilidades subyacentes. Para las personas que han tenido contacto cercano con una persona con COVID-19, la recomendación es realizarse una prueba de detección 3-5 días después de su exposición, incluso si no presenta síntomas; usar mascarilla en público en espacios cerrados durante los 14 días posteriores a la exposición o hasta que la prueba de detección arroje un resultado negativo y aislarse durante 10 días si el resultado de la prueba es positivo (8). Otras recomendaciones del CDC, están relacionadas con los viajeros, y no aplican a la situación de Venezuela. Se debe insistir, además, en el lavado frecuente de las manos y el distanciamiento físico, que el CDC no menciona en este documento. 
Por su parte, la OMS, en un informe para el público, actualizado en junio de 2021, señala que la disponibilidad de vacunas seguras y eficaces supondrá un cambio radical, pero en el futuro próximo se debe seguir usando la mascarilla, en particular en espacios muy concurridos, cerrados y mal ventilados y manteniendo una distancia de seguridad de por lo menos un metro con las demás personas y evitando las aglomeraciones. Insiste además en el frecuente lavado de las manos, la higiene respiratoria y la ventilación de los espacios interiores. Todo esto, sobre todo porque todavía se desconoce el grado en que las vacunas protegen no solo contra la enfermedad sino también contra la infección y la transmisión (9).

A pesar de que esto se repite continuamente por los medios de comunicación y a través de las redes sociales, el personal de salud debe insistir en la importancia de estas medidas, a todo nivel, en la familia, la comunidad, en las aulas de clase y, particularmente, en la consulta médica, aun cuando no se trate de casos con COVID-19; desempeñar ese rol educativo es de suma importancia para lograr que otros se conviertan en agentes multiplicadores de un mensaje que redundará en beneficios para todos.

Hay que pensar en cómo convivir con el virus. Incluso sin inmunidad de rebaño la capacidad de vacunar a los vulnerables parece reducir las hospitalizaciones y las muertes. El personal de salud tiene una enorme responsabilidad en esta lucha con la pandemia, que va más allá de la labor desempeñada hasta ahora en el diagnóstico y manejo de los infectados, y en la investigación en centros especializados. Labor, por cierto, en la que han puesto en riesgo su vida y su salud, y que nunca, por más que se reconozca, el mundo podrá agradecer y honrar lo suficiente a ese personal de salud que se encuentra en la primera línea de lucha contra la enfermedad. Muchos entregaron su vida. Pues ahora, además, los que no están en esa primera línea, juegan un papel fundamental en la educación de la comunidad, en la promoción de la vacunación y del uso de medidas de protección y bioseguridad, $y$ en la orientación en caso de que aparezcan síntomas. Una comunidad bien informada es la mejor herramienta con la que cuenta el mundo para luchar contra las campañas antivacunas. Las vacunas salvan vidas, pero es necesario que la gente se vacune.

\section{REFERENCIAS}

1. Organización Mundial de la Salud [Internet]. Ginebra: Inmunidad colectiva, confinamientos y COVID-19; diciembre 2020 [consultado 25 de agosto de 2021]. Disponible en: https://www. who.int/es/news-room/q-a-detail/herd-immunitylockdowns-and-covid-19? gclid=EAIaIQobChMItY 7M5sbR8gIVDIaGCh31hw51EAAYASAAEgK6n D_BwE

2. Aschwanden C. Why herd immunity for covid is probably impossible. Nature [Internet]. 2021 [consultado 25 de agosto de 2021]; 591:[3 páginas]. Disponible en: https://media.nature.com/original/ magazine-assets/d41586-021-00728-2/d41586-02100728-2.pdf

3. Navarro-Alonso J. Las cinco razones por las que es casi imposible alcanzar la inmunidad de rebaño [Internet]. Asociación Española de Vacunología; 2021 [consultado 25 de agosto de 2021]. Disponible en: https://www.vacunas.org/las-cinco-razones-porlas-que-es-casi-imposible-alcanzar-la-inmunidadde-rebano/?print=print

4. Organización Mundial de la Salud [Internet]. Ginebra: Accesibilidad y asignación de las vacunas; 2020 [consultado 25 de agosto de 2021]. Disponible en: https://www.who.int/es/news-room/q-a-detail/ coronavirus-disease-(covid-19)-vaccine-accessand-allocation

5. OPS: Venezuela recibirá las vacunas del mecanismo COVAX en dos rondas. La Voz de América. 4 de agosto de 2021 [consultado 25 de agosto de 2021]. Disponible en: https://www.vozdeamerica.com/ venezuela/venezuela-recibiria-en-dos-rondasvacunas-de-covax

6. Our World in Data [Internet]. Coronavirus (COVID-19) Vaccinations; 2021 [actualizado 25 de agosto de 2021; consultado 24 de agosto de 2021]. Disponible en: https://ourworldindata.org/covidvaccinations? country $=\mathrm{VEN}$ 
7. Clínica Mayo [Internet]. Variantes de la COVID-19 ¿son causa de preocupación?; 2021 [actualizado 19 de agosto de 2021; consultado 23 de agosto de 2021]. Disponible en: https://www.mayoclinic. org/es-es/diseases-conditions/coronavirus/expertanswers/covid-variant/faq-20505779

8. Centro para el Control y la Prevención de Enfermedades [Internet]. Luego de recibir la vacuna completa. Como protegerse y proteger a los demás; 2021 [actualizado 19 de agosto de 2021; consultado
23 de agosto de 2021]. Disponible en: https:// espanol.cdc.gov/coronavirus/2019-ncov/vaccines/ fully-vaccinated.html\#vaccinated

9. Organización Mundial de la Salud [Internet]. Ginebra: Consejos para el público sobre la COVID-19: vacunarse; 2021 [actualizado junio 2021; consultado 23 de agosto de 2021]. Disponible en: https://www.who.int/es/emergencies/diseases/ novel-coronavirus-2019/covid-19-vaccines/advice 